\title{
O trabalho visto de baixo
}

\author{
Leonardo Mello e Silva, William Vella Nozaki \\ e Vladimir Ferrari Puzone
}

Introdução

É comum a caracterização do tempo presente como pós-fordista e pós-taylorista. Essa é a chave que, na sociologia do trabalho de todo o mundo industrial, abre as vias de interpretação das mudanças que estão ocorrendo no modo de organização das empresas, no seu ambiente econômico, geográfico e social, assim como na experiência dos trabalhadores afetados por essas mudanças. O presente texto irá se debruçar exatamente sobre esse último aspecto, tentando esmiuçar tanto quanto possível o contorno de um fenômeno social de conseqüências não triviais para o desenho de uma modernidade que tem nas relaçóes entre classes sociais o seu ponto forte de sustentação.

Esse fenômeno é justamente o desmanche ou a erosão de uma identidade do trabalho que foi historicamente alimentada por determinadas condições que agregavam, em grandes espaços, massas de homens e mulheres vivendo e experimentando situações relativamente idênticas de exploração e opressão - e que engendraram, como uma resposta a tais situaçôes, formas de resistência e expectativas utópicas de emancipação. É o mundo da "grande indústria", em suma, que está sendo posto em questão. A identidade de classe associada à "velha questão social" cede o passo mais e mais para uma interpelação individualizada da população assalariada, que funcionava até então como portadora simbólica e material de valores coletivos e universalizáveis, mesmo para os não-assalariados. 
1. Agradecemos à professora Heloisa de Souza Martins pelas observaçôes metodológicas feitas à pesquisa, então no seu início, quando de sua já longínqua apresentação em um Encontro da Anpocs. O caminho trilhado desde então deve muito àquelas observações, as quais procuramos seguir.
Esse panorama, que é mundial, afeta também a realidade do trabalho industrial no Brasil.

A experiência considerada emblemática para acompanhar as tendências acima mencionadas é um tipo de organização do trabalho conhecido como “células de produção", encontradas tanto em empresas de setores tecnológica e economicamente de ponta, como naquelas de setores considerados mais conservadores e tradicionais, como o têxtil e o de confecções. A linha de força que ata esses dois pólos está no conjunto de exigências da firma flexível: a conexão com o mercado global por meio de uma cadeia produtiva que implica, de maneira diferenciada e hierarquizada, atores sociais e segmentos produtivos obedientes a uma lógica que lhes é exterior e com reduzida margem de deliberação. Entram nesse caso tanto a montadora de veículos da região do $\mathrm{ABC}$ paulista como, em outro extremo, a empresa que confecciona roupas íntimas para o mercado interno e externo, e também aquela que confecciona capas para assentos de veículos - fornecedora privilegiada da primeira. Como há bastante conhecimento acumulado sobre o universo das montadoras, optamos por deslocar a atenção para aquele que recobre atividades basicamente de corte e costura, e costuma ser menos visível nas considerações algo peremptórias sobre esse gênero de questôes.

Visitas às empresas e aplicação de questionários fechados sobre a organização do trabalho compuseram a primeira parte da pesquisa. Entrevistas abertas realizadas nos domicílios das próprias trabalhadoras complementaram o conjunto de informaçôes que dá a base à análise exposta a seguir ${ }^{1}$.

O texto está dividido de acordo com os principais tópicos que em geral são destacados na experiência de organização de trabalho em grupo ou de uma manufatura celular: são indicações oriundas de leituras de pesquisas feitas no Brasil e no exterior, indicaçôes essas que muitas vezes não são diretas, mas indiretas, o que tornaria enfadonho ou incompreensível arrolá-las aqui. A nosso ver, o importante é o conjunto de problemas que cada tópico levanta, que remete ao objeto explicitado no início, isto é, a experiência do trabalho quando o ambiente microrganizacional conspira para a individualização e o ambiente social perde os referenciais coletivos centrados na classe social.

\section{As células de produção}

Entre as "ferramentas" oriundas dos novos métodos de gestão do trabalho associados à implementação de programas de certificação da qualidade 
e à produção em fluxo tensionado (cf. Durand, 2003) - exigências da firma flexível -, a organização celular talvez seja uma das mais intrigantes, porque combina, em graus variados, coerção e consentimento. Por um lado está o caráter inerentemente antagônico da relação salarial no capitalismo; por outro está o apelo indiferenciado e quase comunal das virtudes sociais do trabalho em grupo. Se é verdade que nos tempos de Taylor e Ford os apelos para a harmonia e a paz social entre patrôes e empregados também faziam parte de seu estoque de doutrinação ideológica (a prosperidade do capital e do trabalho encontrando seu locus na fábrica), não é menos verdade que, no plano dos processos de trabalho reais das firmas ao menos daquelas que aplicavam o método taylorista -, a realidade era bem outra: revoltas contra a imposição de ritmos, contra o poder do controlador do trabalho e contra o ataque aos costumes do ofício (o que envolvia a norma operária de impedir o manuseio de máquinas especializadas por trabalhadores que não fossem do ramo). Eis que o novo modelo produtivo reacende o discurso dos "interesses comuns e complementares" entre operários e patrōes, porém em uma conjuntura duplamente modificada: 1) uma relação salarial fraturada e em recorrente crise, e 2) uma demanda de trabalho industrial que pode prescindir, para ser eficiente, da separação fundamentalista (para Taylor) entre o trabalho de concepção e o de execução - pedra de toque de seu sistema.

Por outro lado, a busca de um comprometimento mais incisivo do pessoal operacional com a produção, tal como se observa hoje entre os administradores e gestores de empresas, não é um simples prolongamento ou atualização da escola de "relações humanas", que, em sua crítica à estreiteza tayloriana simploriamente fincada no homo æeconomicus, "descobriu" a vigência de normas e valores próprios ao grupo social de trabalhadores postos em uma situação de trabalho compartilhada. Contrariamente às abordagens sistêmicas dos primórdios da sociologia industrial, que enfatizavam sobremaneira o ambiente "social" da interação, sem no entanto alargar aquela noção para incluir nela a tecnologia, a própria empresa como feixe de conflitos e a existência de divisões de classe, a ênfase contemporânea na produtividade do grupo está intimamente relacionada com as exigências de qualidade e responsabilidade do aparelho econômico-produtivo. Nesse caso, a produtividade econômica solicita de fato uma "boa" integração de uma parte da força de trabalho desde o início, como componente constitutivo, e não apenas complementar. Prova disso é que as relações humanas diferentemente das segmentações corporativas do passado - estão tenden- 
do a fundir-se nas competências propriamente técnico-especializadas do corpo gerencial, segundo o que têm mostrado as pesquisas.

Por todos esses motivos, pareceu-nos que as células de produção constituem um ângulo de ataque, diante de outros traços possíveis dos novos tempos (a fragilização sindical, a objetivação tecnológica de antigas funçôes profissionais ou a ofensiva contra os direitos trabalhistas, por exemplo), sociologicamente rico e cheio de implicações. Por essa razão elas foram destacadas como matéria de investigação.

\section{A regulação pelo grupo}

O sistema de organização celular é idealmente contraposto ao sistema de produção "em linha". Na verdade, trata-se de duas formas distintas de busca da eficiência produtiva. Embora no início pudesse aparecer dessa forma, a organização celular não é uma alternativa à cadeia de montagem, à classificação funcional e à divisão do trabalho que lhe estão associadas; os dois modelos podem conviver em muitos aspectos-chave, como demonstram a importância atribuída por ambos à qualificação do posto de trabalho e ao controle do tempo de execução das tarefas pelos operários e operárias. É certo que o trabalho em grupo pode estar associado à experiência dos grupos semi-autônomos na Suécia, onde foram postos em prática os ensinamentos da Escola Sociotécnica britânica, mas não é esse o padrão seguido na maioria das aplicações que se constatam em empresas no Brasil. Ao contrário, o trabalho em grupo realmente existente segue de perto o formato da "linearização da produção" implementado pela indústria japonesa no período do boom toyotista, quando os princípios popularizados por Taichi Ohno (entre os quais se incluem o just-in-time e o kanban) se estenderam para outros ramos de atividade. Nesse formato, a preocupação com o desperdício e a ausência de estoques é uma função direta do tipo de racionalização almejado, que é distinto (em certos aspectos fundamentais, é verdade) do tipo de racionalização da produção em massa fordista. Assim, o trabalho em grupo hoje exercitado nas células de produção inclui boa parte do repertório difundido pela chamada lean-production (produção enxuta), ou seja, qualidade, possibilidade de confecção simultânea de mais de um produto quando se aproveita a ociosidade das máquinas, polivalência dos operadores, reuniōes periódicas para discutir pontos de estrangulamento e busca de sugestôes de melhorias, além de outros expedientes que não cabe aqui detalhar. 
A disposição das máquinas, no primeiro caso estudado (fábrica de confecção de roupas íntimas masculinas), obedecia à descrição convencional da chamada "manufatura em U", em que máquinas semelhantes agrupam-se espacialmente em uma seqüência que lembra o desenho da letra $U$, umas posicionadas diante das outras. Trata-se de uma espécie de linha, que no entanto não está dedicada apenas a um único produto. Ao contrário, esse formato permite que vários produtos diferentes em termos de acabamento, mas próximos quanto ao modelo de base, possam ser confeccionados simultaneamente, sem que as máquinas fiquem ociosas quando não ocorrem pedidos. $\mathrm{O}$ ajuste rápido às mudanças sazonais na demanda é evidente, permitindo também maior variabilidade dentro de um mesmo padrão. Cada conjunto de máquinas dispostas em "U" era chamado de "ilha de produção". Uma célula é composta de várias ilhas.

Já no segundo caso estudado (fábrica de confecção de capas automotivas), por se tratar de produtos cujas variações não exigem mudanças de máquinas, mas apenas de corte e de costura que são ajustadas às mesmas máquinas dependendo do tecido, dos pontos de dobra e do acabamento, a disposição não é em " $U$ " mas em duas fileiras paralelas, tendo no meio uma esteira que conduz as capas confeccionadas para um grande depósito em forma de caixa, que deverá em seguida alimentar o estoque e ser então reposto para receber novas capas, e assim sucessivamente. Os estoques não são elevados, tanto pelo reduzido espaço físico da planta como pela organização just-in-time do sistema de fornecimento para o elemento seguinte da cadeia produtiva: as capas vão para uma empresa que as insere nos bancos, que só depois são entregues para as montadoras de veículos. Mas o relacionamento entre as montadoras e a fábrica de confecção de capas é direto e constante, devido às estritas especificações de produto (desenho, tipo de tecido, encaixe das emendas, dimensão etc.). Os representantes comerciais das montadoras circulam freqüentemente pela fábrica, discutindo pedidos e desenhos de produtos.

Tanto num caso como no outro, a representação dos próprios agentes corroborava o senso comum da literatura gerencial sobre a existência de duas "épocas" na vida das fábricas - uma anterior e outra posterior ao emprego da organização celular: o "antes" era o período em que a produção estava organizada em "linha", isto é, em linha de montagem; o "depois" era o período contemporâneo. Nada parecia indicar uma reversão dessa seqüência na vida das empresas, exceto pela memória das trabalhadoras que, em certos momentos, instigadas por perguntas a propó- 
sito de um ponto ou outro do sistema, davam a entender que... antes era melhor.

\section{Antes e depois: a história}

Como as operárias vêem a organização celular na qual elas estão enredadas? $\mathrm{Na}$ empresa de roupas íntimas masculinas, chamada a partir de agora de Empresa A, a avaliação é apenas razoável (43\%), com maior tendência positiva (29\%) do que negativa (19\%). Na empresa de capas automotivas, a Empresa B, a avaliação é mais enfática: $45 \%$ consideraram-na boa, contra apenas $6 \%$ que a avaliaram como ruim. $\mathrm{Na}$ Empresa $\mathrm{A}$, a maioria das costureiras (66\%) passou pelos dois momentos - o sistema "individual", anterior à organização em células, e o atual. $\mathrm{Na}$ Empresa $\mathrm{B}$, a porcentagem era similar (76\%). Portanto, nos dois casos as respondentes estavam em condições de julgar as principais modificações entre um sistema de trabalho e o outro, mesmo que a experiência no sistema antigo não tenha ocorrido na mesma empresa em que agora estão empregadas: metade das operárias na Empresa A vivenciaram o sistema individual (também chamado "em linha", porque apenas um artigo é produzido por vez) em outra empresa, enquanto para a Empresa B esse percentual sobe para 62\%. É certo que a rotatividade e o absenteísmo são problemas freqüentes nas duas empresas pesquisadas (fato que os responsáveis de recursos humanos atribuíram, em ambos os casos, à composição exclusivamente feminina da população trabalhadora sob o sistema de células), o que pode explicar a alta taxa de circulação da força de trabalho: $42 \%$ das operárias que responderam ao questionário trabalhavam na Empresa $A$ havia menos de um ano, ao passo que na Empresa B pouco mais de dois terços do total estavam empregadas havia no máximo cinco anos. Tanto em uma como na outra empresa, a mudança de uma organização em linha para uma organização celular teve lugar na primeira metade dos anos de 1990. Os questio-

2. Maiores detalhamentos sobre essa pesquisa podem ser encontrados em Mello e Silva (2004), capítulo IV. nários foram aplicados no final de $2001^{2}$. A organização mais tradicional, em linha, é muito freqüente entre pequenas e médias confecções.

$\mathrm{O}$ aspecto mais destacado pelas operárias da Empresa A é a possibilidade de realizar várias operações diferentes (39\%), mas um percentual quase idêntico apontou que não há muitos aspectos positivos (34\%). Já na Empresa $\mathrm{B}$, a possibilidade de fazer várias operações diferentes saltou para $70 \%$. O maior contato com as colegas, uma das vantagens mais alardeadas pelo discurso gestionário, ocupa apenas $23 \%$ das preferências na Empresa 
A e 13\% na Empresa B. Já o ritmo intenso é a maior queixa na Empresa A (59\%), enquanto a preocupação com o erro aparece como o aspecto mais negativo na Empresa B (54\%).

A mudança de função - ou de tarefa - por meio da passagem para outras células teve avaliaçôes heterogêneas. A Empresa A deixou entrever que o que aparece na teoria não se verifica na prática, pois $35 \%$ das costureiras afirmaram que a passagem de uma célula a outra ocorre apenas raramente, enquanto na Empresa B 47\% acharam positiva a circulação, devido à oportunidade de mudar de operação. Uma inquirição mais detida mostra que o rodízio de tarefas na Empresa A ocorre muito mais no interior de uma mesma célula (entre as "ilhas" que a compõem) do que entre células diferentes. A confirmação pode ser constatada por meio de outra pergunta, relativa à possibilidade de que as mesmas colegas continuem trabalhando juntas em uma única célula mesmo após a mudança da fábrica: $44 \%$ afirmaram saber que as células seriam mantidas com a mesma composição na nova fábrica. Essas observações talvez exponham a inadequação da formulação inicial da pergunta. No entanto, logo depois da opção que demonstra a tendência de manutenção da célula, aparece um contingente de $25 \%$ que diz encarar com naturalidade a rotação e mesmo preferi-la, uma vez que se trata de uma oportunidade de quebra da rotina. A perseguição, pelas próprias costureiras, de qualificações múltiplas, que porventura possam ser utilizadas fora da empresa, assim como o peso constrangedor do ritmo de trabalho, são os vetores que explicam tal juízo, que, embora não igualmente predominante nos dois casos, freqüenta o ambiente.

As células e as trabalhadoras que as compõem - podemos dizer, seus "átomos" - contam com pouco mais do que elas mesmas para vocalizar suas demandas. $\mathrm{O}$ entropismo da organização, sancionado pelo pequeno mundo da empresa, afasta-as de veleidades de afirmação de classe, fato ainda mais agravado pela tibieza patente da representação sindical: $49 \%$ das respondentes na Empresa A e 60\% na Empresa B consideram o sindicato distante e deixam transparecer certo ressentimento por uma instituição que, embora não totalmente ausente (as que afirmaram "não conhecer o sindicato" foram 27\% na Empresa A e 19\% na Empresa B), não é capaz de "dar muita atenção à base". A desproteção política representada pela instituição sindical ancorase, para sobreviver, nos patamares assegurados pela lei - é da alçada do sindicato a negociação da participação nos lucros e nos resultados e do banco de horas ${ }^{3}$. Mas o ângulo mais perverso da questão está na sua contribuição, inadvertida, à extrema privatização das experiências de trabalho, que se resu-
3. Esses itens da Reforma Trabalhista estão incluídos nos acordos coletivos entre sindicatos patronais e de trabalhadores desde a segunda metade dos anos de 1990. 
4. É oportuno lembrar que a força de trabalho das duas empresas pesquisadas é composta em sua esmagadora maioria de mulheres. No entanto, apenas a empresa maior (cerca de quatrocentos empregados), a de roupas íntimas e meias, possuía creche. mem ao trajeto casa-fábrica nos dias de semana e, quando há horas extras, também nos finais de semana. O papel do sindicato como prestador de serviços em sua sede (serviços odontológicos, médicos, jurídicos e de colônias de férias são os mais comuns) mal esconde o desamparo aparente que é sentido na forma de uma relação longínqua, estranha e que em nada remete ao mutualismo ou à solidariedade comunitária de seus membros, presentes no formato original dessa forma institucional. A deriva de pertencimento público reforça, no nível da organização do trabalho, os valores do empreendedorismo-de-si, quando as operárias lutam para alcançar o prêmio e contra aquelas colegas que não são capazes de fazê-lo.

Paradoxalmente, quando o sindicato é invocado, é apenas para ajudar a assegurar o prêmio (Empresa B), e não para questioná-lo. Eis como o sindicato poderia ser útil para as operárias: contribuindo para aumentar o seu rendimento salarial por meio da confirmação do tipo de expediente posto em funcionamento pela empresa.

\section{A formação de salários: o prêmio}

O sistema de remuneração da organização celular é baseado na incitação salarial direta, e não indireta: essa última, aliás, varia enormemente de uma empresa para outra, no interior de um mesmo ramo (ônibus, restaurante, creche ${ }^{4}$ etc.). É, contudo, no acréscimo salarial conhecido como "prêmio" que reside o maior incentivo ao aumento da produtividade individual de cada uma das operadoras, e a referência para o rendimento no final do mês, mais do que o salário fixo, que é muito baixo.

O prêmio depende do alcance das metas de produção estabelecidas pela direção. No sistema dito "individual", próprio da produção "em linha", o prêmio dependia do esforço de cada operadora em seu posto de trabalho, envolvida nas tarefas relacionadas a ele. Esse prêmio era, por assim dizer, administrado por si mesmo, isto é, pela própria trabalhadora, na medida de um cálculo que opunha, de um lado, o conhecimento das próprias possibilidades e, de outro, a resistência do equipamento, dos materiais e dos instrumentos postos à disposição, todos eles conhecidos e aos poucos "domados" pela prática repetitiva que o trabalho impunha. No sistema de células, o cálculo muda, porque o ajuste entre trabalhadora e ambiente inclui agora as próprias colegas, que fazem as vezes do fornecedor e do cliente do trabalho efetuado por cada operadora individualmente. Nessa concepção de posto alargado, a trabalhadora individual depende de manei- 
ra muito mais estreita das colegas, que estão implicadas forçosamente (pela detenção de uma parte do trabalho da outra) na atividade dela.

No entanto, disso não decorre uma intercomunicação ${ }^{5}$ que, pela atividade operativa que ata uns e outros, estabelece uma teia produtiva em que a limitação do trabalho individual e seu entorno (no sentido que conduz à noção de trabalho como "obra", segundo a concepção aristotélica recuperada por Hannah Arendt) explode em benefício de um trabalho coletivo, que alarga a dimensão do trabalhador solitário obrando o seu objeto por meio do instrumento próprio dele. E não o faz porque o obstáculo a uma sociabilidade que nasça do trabalho reside na forma que envelopa a seção e a empresa, qual seja, a forma social que impõe um ritmo e uma organização ao processo de trabalho cuja inteligibilidade não reside no processo em si. Uma das manifestações desse obstáculo é a própria relação salarial, que paira como orientadora de sentido para a racionalização que os atores fazem de seu próprio trabalho. Quando, portanto, a responsabilidade pelo alcance da meta (e do prêmio) transfere-se daquilo que é bem estabelecido na trabalhadora individual para o imponderável do grupo, o atrito entre a solicitação das atividades dos outros como complemento da atividade de cada um e a certeza do que é possível extrair a partir de si mesmo expóe toda a sua gravidade, pelo fato de a operadora recusar essa participação com receio de não poder manter ergonômica e significativamente o seu próprio trabalho.

Vale lembrar que nas formas de solidariedade pré-tayloristas fazer o trabalho do colega era, ao contrário, indigno e uma maneira de minar a confiança do grupo, já que ia de encontro às quotas impostas pelo próprio grupo a fim de amarrar a produção. As quotas eram bastante rígidas, não variando nem com o regime de trabalho por peça em diferentes seções de uma mesma indústria. Em 1902, em uma fábrica de equipamentos agrícolas mencionada por David Montgomery (1980, pp. 12-13), os departamentos de polimento, prova, ferraria e máquinas ganhavam todos mais ou menos a mesma soma, a despeito da enorme diferença de tempo de execução e grau de dificuldade para cada uma dessas atividades. Aquela combinação recíproca era muitas vezes apoiada pelo sindicato, embora não o fosse necessariamente. Na virada do século XIX para o século XX, em alguns setores era proibido pelo sindicato que o afiliado ficasse responsável por mais de uma máquina ao mesmo tempo, ou aceitasse pagamento por peça (cf. Idem, p. 15). Regras estabeleciam, por exemplo, a velocidade com que cada um deveria trabalhar. Eram, portanto, regras estritas, que diziam respeito a como efetuar o trabalho.
5. Philippe Zarifian (1998) sustenta resolutamente essa possibilidade nos processos produtivos modernos, mas baseando sua argumentação em setores tecnologicamente mais sofisticados e dependentes de uma sólida qualificação dos operadores-setores, portanto, diferentes daqueles que são objeto de nossa pesquisa. 
6. Uma boa recensão encontra-se em Fournier (1996, pp. 80-93). As datas entre parênteses referem-se ao ano de publicação dos resultados das respectivas pesquisas.

7.O individualismo tayloriano fica pouco à vontade aqui, pois a incitação salarial, em nosso caso, não chega até ao ponto de diferenciar uma operária da outra, esbarrando nessa figura do "coletivo" que é a célula. Assim, mesmo que cada operadora não se esforce, não produza, o grupo garante o prêmio.
O sentido de igualitarismo partia da autonomia e da diferença de cada ofício específico. O passo seguinte do taylorismo foi atacar esse bastião de controle operário sobre o próprio trabalho, trazendo também um igualitarismo renovado, dessa vez por subtração: trabalhadores expropriados do ofício, servos do sistema de tempos e movimentos, possuem em comum o desenraizamento dos antigos códigos de honra e de ajuda mútua, agora partes superespecializadas de um mecanismo.

Do mesmo modo, esquemas socialmente construídos por grupos de trabalhadores para "restringir a produção" são conhecidos mesmo para períodos posteriores à vaga de conflitos que envolveram os profissionais de ofício em sua luta para manter a autonomia do próprio saber-fazer (início do século XX), e ficaram célebres como estudos paradigmáticos da sociologia industrial, desde Elton Mayo (1933), passando por Donald Roy (1954), até Michael Burawoy (1979) 6 . Todos esses exemplos indicam que a sociabilidade do grupo operário passa pela forma como se processa o ajuste interno dos "trabalhos" de cada um dos membros, em um embate entre a norma de rendimento imposta e a "quota" estabelecida pelos próprios trabalhadores.

No universo de nossa pesquisa, do ponto de vista da formação dos salários, a passagem do sistema "individual" para o sistema de "célula" envolve também o deslocamento da mensuração baseada na produtividade individual para uma mensuração baseada na produtividade da célula ou do grupo. No sistema "individual", o prêmio era proporcional à quantidade produzida além do padrão, e era também cumulativo: para uma quantidade suplementar à "extra", havia um prêmio adicional. Hoje, ele é distribuído coletivamente para os membros da célula. Como o balanceamento da produção é também atribuído à célula, ou seja, é ela quem deve dosar as quantidades de produtos semi-acabados de modo a impedir os tempos mortos em cada ponto em particular da "ilha", é também dela a responsabilidade pelo ajuste salarial do grupo. Aliás, a transparência crua da relação entre rendimento e resultado do trabalho, seja no formato individual, seja no formato coletivo de mensuração da produtividade, só é possível pela eliminação paulatina das formas sociais de mediação entre a relação salarial e a expressão da existência no seu nível mais elementar, instaurando uma semântica completamente commodificada para traduzir as relações de trabalho.

Na Empresa A, o prêmio é coletivo, não é individual: mesmo que não se esforce, não produza (tanto), o grupo garante (algum) prêmio ${ }^{7}$. O prêmio 
pode induzir as pessoas a ajudar umas às outras ou pode fazer com que cada uma tente levar a melhor sobre o colega? Muitas pessoas não utilizam o tempo livre para ajudar os outros, embora possam fazê-lo. Aqui, a responsabilidade do ajuste de quem trabalha mais e quem trabalha menos é do grupo: é ele quem fica com o fardo de cobrar desempenho de seus membros. Mas, por sobre esse ajuste social do grupo (uma operária pode não ajudar outra por quem tem antipatia ou inimizade, por exemplo), há a norma salarial da empresa: se cada ilha tem uma performance e um resultado diferentes, a resultante em termos de distribuição do prêmio segue o valor mais baixo. A regra funciona do seguinte modo: se a primeira ilha atinge $100 \%$ de sua produção, mas a segunda e a terceira ilhas não atingem o mesmo índice, no final do dia a ilha que fez $100 \%$ ganhará apenas $80 \%$ do prêmio. "Quem fez 100 vai ganhar 80 igual às outras, umas trabalham mais do que as outras", diz a informante. A célula considera-se portanto injustiçada, porque, dentro de uma ilha, umas produzem mais do que outras. "Tem que ser todo mundo igual”, diz a mesma informante. Mas, no fundo, o que prevalece é um sentimento de resignação: "Todo mundo vai ganhar mesmo igual, não adianta ficar discutindo...”. Só que ganhará menos em relação à produtividade que poderia ser alcançada individualmente.

A expectativa da informante é de que, atingida a meta, a costureira ajude outras colegas no decurso do tempo que lhe resta. Se a trabalhadora mais produtiva não o faz, acaba reduzindo a produtividade da "ilha" inteira. Mas o fato é que muitas trabalhadoras não utilizam o tempo livre obtido ao terminar antes a operação para ajudar suas companheiras. Na verdade, existem aquelas operárias que "completam" o trabalho das outras - talvez em razão do tipo de tarefa a que estão destinadas pela organização, sem uma especialidade muito definida -, em cada célula ou entre células diferentes, o que de certo modo dispensa as operadoras de correr atrás do trabalho excedente das demais. Mesmo assim, a responsabilidade do ajuste sobre quem trabalha mais e quem trabalha menos é do grupo: é ele que tem a responsabilidade de cobrar as colegas. Se, por um lado, quem se esforça mais não tem esse diferencial sancionado pelo prêmio (o que vai de encontro ao ideal taylorista de individualizar o rendimento com base na tarefa), por outro lado o grupo pode rebaixar o prêmio do membro que, segundo seu juízo, não esteja se esforçando suficientemente. O poder "coletivo", portanto, não é pequeno: por um lado, e perversamente, como se viu, impede que a média da produtividade caia demasiadamente (pois isso implicaria um prêmio subtraído da possibilidade de 100\%); por outro lado, arroga-se a capacidade discricionária de indicar aquele que não "dá tudo 
o que pode", ou que tenta aproveitar-se dos colegas, preservando-se ou simplesmente adotando a conhecida estratégia do "carona" (free-rider). Se esse comportamento ocorre, o grupo pode reduzir o prêmio da colega a $50 \%$ ou mesmo a zero, e pode ainda, a seu escrutínio, conceder o prêmio à operadora que demonstre "força de vontade em ajudar", mesmo sendo menos produtiva.

O sistema de células encontra-se, assim, embebido no reino do arbitrário, o que lhe confere sua força, mas também sua fraqueza, caso não seja bem "ajustado". A fraqueza está relacionada com a dificuldade de estabelecer uma medida objetiva própria do trabalho. No entanto, isso não significa a existência de um vazio, pois, como se viu, a norma salarial da empresa paira sobre todas as costureiras. O que é importante notar aqui é que, por um lado, trata-se de uma discussão interna à célula, não entre a célula e a encarregada ou supervisora, daí o ajuste "pelo grupo"; por outro lado, quando se trata de ajuste salarial, na verdade ele não é feito pelo grupo, e sim sobre o grupo. Isso explica a percepção entre as operárias de que "antes era melhor": "Hoje todo o mundo trabalha como um grupo [...]. Quando todo mundo trabalha unido, é bom; mas, quando cada um quer ver apenas o lado dela [pessoa] e não quer ajudar os outros, é melhor trabalhar individual", quando "cada um fazia a sua parte" (costureira, célula 14, com 19 anos de casa, que passou pelos dois momentos da "linha" e da "célula"). Antes, o ganho dependida apenas do "esforço" de cada um; hoje depende do "esforço" dos outros - daí a confusão, a briga.

A administração intestina da célula insere-se entre tendências contraditórias, difíceis de compatibilizar. Se o bom senso do grupo reza que, atingindo a meta, cada costureira tem que ajudar as outras, a realidade é que o ritmo de trabalho pode conspirar contra. Assim:

Tem como fazer isso [ajudar as colegas]. Nem todas conseguem fazer. Eu não posso ajudar outras porque o tanto que eu tenho que atingir, não tenho tempo para isso. Mas a outra costureira que tem que me ajudar, ela tem tempo de ajudar em outro lugar, porque ela só vai completar a minha parte e ajudar em outra operação [trata-se da operária que "completa” os trabalhos, conforme já mencionado]: dá para fazer isso. Tem discussões, por mais que explique lá isso direitinho, que tem que trabalhar unido, trabalhar junto, mas sempre tem essas discussōes... (costureira, célula 14).

A encarregada só se envolve quando é chamada ou em ocasiōes em que é preciso fazer realocações de costureiras por ausência, férias ou outro fator qualquer, contanto que seja observado que a operadora a ser retirada "não 
vai fazer falta”. Pelo procedimento padrão, a encarregada checa se o problema é realmente com o fator humano, se não se trata de um problema na máquina ou de inadequação da operadora (por causa de sua capacitação, qualificação ou ambientação ao posto) ao maquinário e à operação, ou simplesmente por "falta de serviço" - dessa forma funcionando como um contraponto a uma possível arbitrariedade da célula. A encarregada pode propor então uma nova operação para a costureira recalcitrante ou sua transferência, trocando com outra operadora de outra célula. A exclusão é o último recurso, mas acontece. Quando o problema detectado não é técnico, mas humano (como problemas de "relacionamento"), a dispensa parece ser mesmo a única alternativa.

Nesse ponto, surge a questão - delicada - da evicção de um membro do grupo.

Confrontadas pela pergunta de se, caso alguma companheira de seção manifestasse dificuldade em realizar uma tarefa, as operárias procurariam ajudá-la ou, ao contrário, continuariam fazendo sua própria tarefa, a resposta foi inequívoca nas duas empresas: 77\% na Empresa A e 63\% na Empresa $\mathrm{B}$ responderam que não diminuiriam o próprio ritmo para não comprometer a meta da célula. $\mathrm{O}$ comportamento orientado estritamente para metas condena os menos produtivos a saírem do "coletivo".

Ora, como é processada socialmente tal exclusão? O primeiro procedimento metodológico necessário é deixar de lado qualquer tomada de posição essencialista na apreciação dos comportamentos - quer de ultraje, quer de melindre, quer de frieza - dos membros dos grupos de trabalho: como produtos do meio social que oferece as balizas de sentido para os atores, essas reações só são inteligíveis no quadro da "naturalidade" construída da situação. Dito isso, o segundo procedimento metodológico deve ser o de entender (e explicar) esses comportamentos.

\section{A exclusão do grupo}

Aparentemente, o mal-estar moral advindo da exclusão do outro não é suficientemente constrangedor para fazer frente ao poder onipresente do prêmio. Todas as entrevistadas sancionaram a lógica mercantil que subjaz a ele. Mas a situação terrível que essa decisão acarreta transparece no cuidado em colocar-se fora do drama. A informante mais velha faz questão de marcar que nunca passou por isso. O julgamento é transferido para outros, deslocado do campo da decisão que lembra o desagradável da situação. Por outro lado, a 
8. Mesmo que os gerentes não acreditem realmente naquilo que veiculam, não se pode ignorar o poder persuasivo da repetição, uma das características precípuas da doutrina. Não se pode saber até que ponto os gerentes e supervisores acham de fato na ausência de um discurso antagonista - que as células podem preencher um espaço de convivência social. decisão do grupo também não é indeterminada; ela é limitada pelos movimentos do tipo sístole-diástole que o desenho flexibilizante do modelo produtivo impõe à vida da fábrica. A empresa pode diminuir parte do contingente da célula devido à falta de demanda dos clientes, por oscilaçóes no mercado de produto, pela concorrência capitalista no ramo ou simplesmente devido às férias de algumas operadoras. O estado mais ou menos endêmico de crise dos setores ligados à produção manufatureira no Brasil, com seu horizonte tímido em termos de planejamento, alternando crescimento e estagnação em períodos curtos de tempo, conspira para agravar a oscilação das posições e das qualificações dentro do processo de trabalho. Assim, começa a fazer parte do costume dos assalariados da geração pós-reestruturação produtiva a sensação de instabilidade permanente como regra. $\mathrm{O}$ arranjo equilibrado da célula, se alcançado, dificilmente poderia durar muito. De todo o modo, ainda que com o aguilhão representado pela inserção na cadeia produtiva a desempenhar o seu papel, é preciso enfrentar as escolhas. Então, o que se faz quando alguém tem de sair? "Quando a gente trabalha há bastante tempo junto com a outra, fica meio confuso, meio complicado, né?, a gente ter que resolver isso: ter que tirar uma pessoa do grupo." No caso prosaico de uma costureira tirar férias e ser substituída por outra, que acaba se revelando mais produtiva, mais cooperativa do que a titular, surge de novo o dilema: o grupo acaba se acostumando com o novo membro, que lhe dá uma fluidez melhor, e "esquece" a primeira, de modo que, quando ela volta, seu lugar está ameaçado. "É uma decisão muito difícil”, tomada em reuniōes que acontecem no próprio horário de trabalho. "Vai mais pelo prêmio, e não pela amizade. Se você não atinge, você não ganha. É complicado... A pessoa pensa mais no prêmio, no que ela vai ganhar no fim do mês."

No entanto, quem é esse "outro" que convive lado a lado nas células? Uma assalariada indiferenciada, que sanciona a identidade geral de força de trabalho, ou uma "parceira", uma "colaboradora", uma "colega", que sanciona uma identidade privada de membro da coletividade da empresa, segundo o discurso apologético da gerência ${ }^{8}$ ? Isso nos remete à nossa próxima questão.

\section{Critérios para a composição das células}

O critério para a composição humana das células é definido pela especialidade da operação, e não por qualquer atributo "social" anterior. $\mathrm{O}$ constrangimento técnico é aqui preponderante: ele agrupa as pessoas que 
sabem fazer determinado tipo de artigo, como na época do trabalho individual. Não há a interveniência de aspectos como a amizade ou a vizinhança, por exemplo. Portanto, o elemento da qualificação do trabalho é ainda determinante na manufatura celular e está associado simultaneamente ao tempo do "trabalho individual", conforme é lembrado de imediato pela costureira com maior tempo de casa da amostra.

Quando as células foram montadas, escolheu-se, para cada artigo, o conjunto das costureiras que já se dedicavam à confecção daqueles produtos (meias e cuecas, basicamente), de modo que não houve uma ruptura muito pronunciada. Isso pode explicar a relativa indiferença e até mesmo espanto pelo marco epocal sempre evocado na narrativa tanto gerencialempresarial como dos pesquisadores que fazem suas primeiras incursões ao campo buscando os sinais evidentes da "mudança" ocasionada pela aplicação de novos paradigmas produtivos. Ao contrário, do ponto de vista do trabalho efetivamente executado, a mudança não parece ter sido tão significativa, exceto pelo acréscimo de especialidades diferentes no novo formato celular, o que de fato é uma novidade em relação ao trabalho individual, quando cada uma fazia um determinado artigo. Hoje, há células que chegam a fazer dois ou três artigos diferentes, cada um deles com o seu tempo, o que altera o ritmo individual e causa também problemas de desbalanceamento no interior da célula.

A mudança, no caso, não é vista pelas costureiras com surpresa, sobretudo porque não alterou as formas consagradas de realizar o trabalho, mas tão-somente marcou o início de uma "nova fase" na vida da empresa, uma deliberação de cima para baixo que realça novas metas, novos objetivos (produtividade, qualidade do produto, competitividade da qual depende os esforços individuais e coletivos etc.): é sob a marca de um discurso que enfatiza a nova "missão" para a qual elas foram convocadas que se situa o entendimento do antes e do depois (trabalho em grupo e trabalho individual) entre as operárias. E é isso também o que torna compreensível para elas a nova orientação que estão abraçando, o que fica bem evidente nas justificativas para a introdução do sistema de produção encontradas nos depoimentos, com toda a panóplia de certificações e a obsessão por medições que o acompanha: a repetição enfadonha (pelos elementos mais "esclarecidos" entre as trabalhadoras, em especial o pessoal de supervisão) dos mesmos argumentos convencionais (técnico-econômicos) da gerência num quadrante "popular" revela o enorme esforço de processar a linguagem objetiva da organização em um discurso plausível para um interlocu- 
9.E que é tão mais solitária na medida em que não é captada por nenhuma forma institucional, nem na empresa, nem fora dela. tor universitário; esforço esse que é tão maior quanto mais aqueles vetores normativos que são realçados não correspondem a uma real experiência de trabalho. Mas exatamente porque são "vazios" de experiências é que eles fornecem a chave do entendimento de toda a agitação em torno de células, ISO, estoques, ordens de produção em inglês, visitas de clientes e outras transformaçōes visíveis na vida da fábrica. A sensação corrente é de que alguma coisa muda, mesmo que não se saiba exatamente o que. Isso é válido tanto para a Empresa A como para a Empresa B.

No entanto, isso não quer dizer que a percepção das diferenças entre o sistema individual e o celular não tenha nenhuma repercussão na forma de se trabalhar - a diferença, aliás, está exatamente na forma e não no conteúdo do trabalho. Fazer mais de um produto em uma mesma jornada requer um ajuste na passagem de uma operação a outra: perde-se tempo e há a necessidade de se acostumar ao novo ritmo, algo bem conhecido pelos estudos de organização do trabalho. Como o prêmio é atribuído em função da quantidade, o tempo gasto nesse ajuste é um fardo. São duas linhas de força que empurram para sentidos contrários, o que alimenta uma angústia perceptível em muitos depoimentos': exige-se um patamar elevado de produção de um determinado artigo e, ao mesmo tempo, com a mudança de artigo aumenta-se o tempo "perdido", que havia sido ganho com o costume na dedicação à operação anterior. Contudo, a possibilidade de uma única célula confeccionar mais de um artigo está na base da virtude do modelo, uma vez que responde às exigências de flexibilidade da demanda. Nesse ponto, o círculo se fecha - como na equação do binômio qualidade $e$ quantidade, exigências que às vezes parecem incompatíveis.

Outro gênero de problema comum na dinâmica da simultaneidade produtiva ocorre quando se tem de retirar uma costureira da célula porque o novo artigo a ser confeccionado não exige todo o contingente anterior, $o$ que desloca essa trabalhadora para uma nova célula, onde ela possa fazer uso de sua capacitação. O sucesso da acolhida na nova célula depende da disponibilidade de um posto do mesmo tipo do que havia na célula de origem, o que pode não acontecer. Daí a importância da polivalência: ao aumentar a oferta de tarefas possíveis a serem realizadas por uma única operadora, crescem as chances de encontrar um lugar para a costureira vaga em um momento em que não é solicitada por um novo arranjo do mix de produtos da empresa. A migração para uma nova célula, que representa igualmente a inserção de um corpo estranho em um grupo já constituído, desorganiza o arranjo social no destino. 
Se o conteúdo da operação não muda, a agregação de diferentes trabalhos significa um esforço suplementar num posto que se alarga com a incorporação de novas tarefas. Afinal, mesmo quando se trata de uma única máquina, os trabalhos podem ser bem diferentes de acordo com os modelos: a operação de uma galoneira para um determinado modelo, por exemplo, não quer dizer uma transição sem solução de continuidade para a operação da mesma galoneira em outro modelo: "Para quem não está acostumado, fica complicado, né?" (costureira, célula 14). A contraprova dessa segmentação de tarefas, que no fundo permanece, é o treinamento dispensado para aquelas costureiras que, ao terem de mudar, são apresentadas a uma situação na qual não podem desempenhar suas tarefas sozinhas. $\mathrm{O}$ treinamento ${ }^{10}$ injeta, de maneira esquemática ${ }^{11}$, o conteúdo que preenche o déficit de certo saber de ofício, ou então - o que é uma alternativa totalmente oposta à primeira situação - apresenta uma especialidade totalmente nova e específica, às vezes intransferível para outra empresa. Mas, como quer que seja, a situação de treinamento é uma situação de desvalorização econômica evidente: o prêmio cai, chega no máximo a $80 \%$ para a operária individualmente ou para o grupo com a costureira em treinamento, uma vez que o habitus produtivo duramente alcançado é desestabilizado. A desorganização observada no nível individual repercute diretamente no nível do coletivo, da célula.

Fica claro que a polivalência, nesse formato específico de manufatura celular, não tem nada a ver com o espírito dos grupos semi-autônomos de organização do trabalho. Trata-se de uma maneira de alocar rapidamente uma nova peça no mecanismo, sobretudo em um ambiente no qual o absenteísmo fustiga o planejamento da relação tecida entre elemento humano e máquinas, bastante presente em um tipo de produção trabalhointensivo. Os problemas de balanceamento da produção como um todo, incluindo a relação mencionada acima, tornam-se, do ponto de vista da gerência, mais complexos. Do ponto de vista do trabalho, que é o que nos interessa neste artigo, eles marcam uma mudança em relação à fixidez do estilo taylorista-fordista de organização e projetam uma situação de incerteza mais ou menos permanente na força de trabalho submetida a esse tipo de método. Ela sabe que o tempo de permanência no posto se estreita e que passa a ser sua a responsabilidade de "se virar", de encontrar alguma coisa melhor quando a vida útil no posto (ou na empresa) tiver se esgotado. Isso certamente terá repercussões na experiência de classe, na medida em que esses métodos se generalizem.
10. Existe um treinamento básico, inicial, que é diferente do treinamento especializado, para quem já está dentro. Quando entra uma costureira nova, o tempo médio de treinamento antes de ir para a célula é de aproximadamente 1 mês.

11. O treinamento, ao menos na conjuntura das visitas, não era incorporado como elemento estratégico da empresa. $\mathrm{O}$ treinamento "universal" em todos os tipos de máquinas, embora fosse computado como importante, apenas podia ter lugar nos momentos de folga de pedidos, o que parecia algo raro.

novembro $2005 \mathbf{3 6 7}$ 
12. Para uma abordagem compreensiva, é interessante consultar os relatos sobre o taylorismo realmente existente, e não como tipo-ideal; para isso são imprescindíveis os trabalhos de Montgomery (1980) e Nelson (1984, pp. 51-66).

13. Essas observações são devidas a Robert Cabanes, em uma discussão preliminar desses resultados.

\section{0 treinamento e seus ardis}

Um bom posto de observação para perscrutar essa percepção difusa, ao mesmo tempo de deriva e de esforço para recuperar uma posição de classe ameaçada, é o treinamento. $\mathrm{O}$ aspecto ambíguo do treinamento emerge quando ele passa a ser encarado, pelas costureiras, não como um incremento da qualificação para a empresa, mas como uma agregação de conhecimento útil para uso próprio, em uma estratégia individual que não inclui a empresa como meta final. Esse aspecto é bem conhecido tanto das gerências, com sua lógica marginalista, como dos cientistas sociais, com a ênfase na lógica social que informa a escolha dos atores. No primeiro caso, o dilema é real e acossa boa parte do bom senso organizacional: para que investir tanto no treinamento se os mais bem treinados... vão embora? Para atraílos, seria preciso a um só tempo reduzir os fatores de turn-overe tornar mais atraente a remuneração - dois problemas, aliás, que o taylorismo e o fordismo históricos resolveram ao seu tempo (cf. Ford, 1954; Taylor, 1987) ${ }^{12}$. Mas deixemos com os gerentes (e economistas) a resolução desse dilema. Vejamos o segundo caso, o da lógica social que está por trás das escolhas em "sair" ou "ficar". A primeira coisa que chama a atenção é a fragilidade dos temores totalizantes de que a empresa envelope toda a vida do trabalhador, isto é, que ela o faça "vestir a camisa" e cancele todas as diferenças entre as suas escolhas pessoais e as escolhas da firma. Mesmo que esse excesso de integração seja sancionado pelos êxitos sucessivos na teia de adulação que a empresa monta para atrair operários e operárias com boa performance, o perigo de "queda" no mercado de trabalho ${ }^{13}$, isto é, de dispensa, está sempre à espreita, desfazendo portanto o idílio de que empresas e trabalhadores formam um só corpo. Em segundo lugar, essa escolha é em boa medida sobredeterminada pelas próprias condições do mercado de trabalho (como também na época de Taylor e de Ford): salários atraentes do concorrente em situação de não-monopólio. Mas é na inserção em um projeto de vida coerente dos agentes - que pode incluir a empresa ou náo - que essas escolhas devem ser enquadradas. De todo o modo, o uso da qualificação terá uma ponderação aqui que depende de muitas variáveis, as quais fogem do universo do processo de trabalho. Muitas costureiras aderirão ao treinamento porque "acham uma coisa boa pra elas porque... a gente não fica a vida inteira em uma empresa só! Você, saindo daquela empresa, já tem condições de trabalhar fora numa coisa até diferente daquilo que você faz; é mais fácil pra você [...]”. 
A polivalência, ademais, aponta para um incremento do salário: o treinamento dentro da empresa, isto é, a capacitação para operar três ou quatro máquinas, implica ganhos maiores. Desde que o treinamento acarrete um ganho efetivo na produtividade da operária: "Você teria que produzir, não só aprender. Porque só aprender, pra eles, não é um resultado. Você tem que saber produzir naquela função que você tá fazendo" (costureira, Empresa A). O pragmatismo do treinamento exige da contraparte que foi treinada o "resultado", e esse contrato é desde logo bem entendido por ambas as partes, a do capital e a do trabalho. $\mathrm{O}$ treinamento, do ponto de vista da empresa - o que é também imediatamente captado pelo seu destinatário -, não é uma dávida ou um conjunto vago de conhecimentos que se dissipa em uma aquisição abstrata, mas, ao contrário, exige uma aplicação imediata, uma prova; numa palavra, trata-se de uma espécie de bem-estar carimbado, transferindo para a situação de trabalho a mentalidade presente no procedimento do tipo means-tested - o modelo liberal de auxílio aos realmente necessitados, segundo a classificação proposta por Esping-Andersen $(1990)^{14}$ para os formatos exemplares de proteção social do capitalismo.

Mas o olhar voltado para o lado de fora, como se verá, tem sua razão de ser.

\section{Se ficar o bicho pega, se correr o bicho come}

Em fins de 2001 e início de 2002, a fábrica de confecção de roupa íntima masculina, então exclusivamente de capital nacional, transferiu-se da Zona Oeste da cidade de São Paulo para um município limítrofe, como resultado da aquisição por uma empresa norte-americana, que preferiu centralizar toda a atividade produtiva do grupo naquele ramo em um único lugar. Pouco tempo antes, o questionário pôde aquilatar o estado de ânimo das trabalhadoras quanto a essa mudança: $60 \%$ delas afirmaram preferir que a empresa permanecesse onde estava. De fato, o temor tinha fundamento. Com a mudança da fábrica, algumas operárias, as que moram no extremo oposto da cidade (Zona Leste), foram dispensadas, evidenciando um corte geográfico nítido: três horas de ônibus entre o local de moradia e o local de trabalho pareceu inviável para a direção - as operárias chegariam muito cansadas e o custo do transporte em ônibus da empresa também sairia muito caro. A expectativa do pessoal, inclusive o que ficou - a maior parte, portanto -, era de que, aos poucos, o antigo contingente fosse substituído por outro composto de pessoal da região. Nesse sentido, a mudança
14. O primeiro capítulo deste livro foi traduzido para o português na revista Lua Nova, 24, set. 1991. 
15. Os ônibus conduzem as trabalhadoras no trajeto casa-empresacasa. Por vezes, costureiras vizinhas não tomam o mesmo ônibus devido aos percursos, que podem ser mais próximos do local de moradia de uma delas, embora não fique longe da moradia da colega. de local da fábrica já é uma indicação de que, não a curto prazo, mas certamente não num período muito longo, os dias de emprego estão contados. Isso é de certa forma confirmado pela responsável de recursos humanos, que confidenciou a preferência pelo pessoal novo (mulheres) do local, inclusive com programa de treinamento direcionado para esse fim e com suporte do Senai. A mudança, além da instabilidade inerente ao mercado de trabalho em uma conjuntura de crise, é um sinal a mais a relembrar a insegurança do estatuto de empregado(a). Os dois fenômenos - enxugamento e deslocalização - são, aliás, faces da mesma moeda da reestruturação ampla das firmas. As próprias operárias residentes na Zona Leste por fim teriam percebido a irracionalidade da situação: o gasto elevado com transporte (se fossem arcar com ele por si mesmas) e a inevitável indisposição depois de enfrentar o trânsito até chegar à empresa - feitas as contas, não valeria mesmo a pena. Mas essa não foi uma escolha que lhes tivesse sido apresentada. Com a palavra, uma operária que ficou: "Quando era em São Paulo, eu levantava às cinco e meia; para ir para o novo endereço, levanto às quatro horas. E de São Paulo até a minha casa, cinco e meia ou quinze para as seis eu já estava em casa; do novo endereço pra cá, eu chego às sete horas. Então, tem uma diferença grande". O tempo de transcurso, no geral, aumentou para boa parte delas, à exceção das que moram mais perto do novo local. Mas, pelo fato de a empresa ter de arcar com o transporte para o pessoal de São Paulo (e isso significa custo: fretamento de ônibus ${ }^{15}$ ou vale-transporte), a percepção disseminada é de que talvez a situação não dure muito tempo mesmo para as que ficaram. $\mathrm{O}$ espectro da substituição pelas novatas passa a ser um dado, um perigo iminente:

[Ao] pegar pessoas das redondezas, que são mais próximas, para ficar no lugar da gente... Nós vamos ser... seríamos dispensadas. A gente mesmo fomos pra lá com esse pensamento - talvez não era o que eles [a empresa] estavam pensando, mas foi o que a gente mesmo estava pensando - que não seríamos mantidas.

O questionário permitiu, de um outro ângulo, avaliar a importância do emprego para esse grupo operário, que compensa todos os obstáculos: perguntadas sobre o grau de interferência da mudança da fábrica em suas vidas, $42 \%$ delas respondeu que não importa para onde a fábrica vá, o importante é continuar empregada; $41 \%$ queixou-se da distância entre casa e trabalho; e 13\% afirmaram não pretender continuar trabalhando na empresa em sua nova localização. 
As dispensas, contudo, não tiveram como único motivo o local de moradia. Quando há uma deslocalização produtiva, ela pode vir acompanhada de uma reversão ou modificação de partes do processo de trabalho; mas não foi esse o caso da empresa de confecção em questão. As operações (funções) mantiveram-se as mesmas, o que sugere a idéia (e confirma a percepção popular) de que a empresa possa ter aproveitado a oportunidade para simplesmente se livrar de uma parte de sua população trabalhadora. A organização celular também não foi desmantelada com as mudanças, já que as pessoas dispensadas estavam distribuídas pelas células - não foram escolhidas de uma única célula -, demonstrando certa indiferença quanto ao sistema organizacional e os conseqüentes transtornos na força de trabalho.

Por outro lado, o "tempo de casa" em uma firma renomada pode funcionar como uma marca facilitadora do acesso a outra empresa, como no caso da Empresa A, e também como "escola", pois as outras empresas do ramo chegam a dispensar a necessidade de treinamento para uma função equivalente quando contratam essas trabalhadoras.

\section{Flexibilidade como regra e seus efeitos na qualificação}

É comum ocorrer a mudança de produtos ou artigos manufaturados em uma mesma jornada, o que acarreta perda de tempo e desorganização do hábito (adequação entre operador e máquina) já obtido e "estabilizado"16 com certo esforço, como se viu anteriormente (ver a seção "Critérios para a composição das células") - afinal, leva tempo para a operadora acostumar-se a uma nova máquina. $\mathrm{Na}$ Empresa $\mathrm{A}$, a introdução de um novo modelo em determinada célula, por exemplo, transferiu o artigo ali confeccionado para outra célula (a de nossa informante), que assim passou a produzir dois produtos diferentes, o antigo e o novo. Há casos, contudo, em que a célula, ao ser montada, já começa produzindo dois modelos em vez de se especializar em apenas um. É certo que a diferenciação entre os modelos pode esconder uma forte semelhança em sua manufatura, mudando apenas o número de referência (código) do produto: em outras palavras, os modos operatórios exigidos não são muito díspares, levando a uma adequação mais tranquiila. Mas há situações também em que isso não ocorre: o novo modelo é bastante diferente e exige um esforço de adaptação, sendo necessária a utilização de tipos diferentes de máquina pelas operadoras para dar conta dos pedidos. Nesse caso, as novas máquinas são trazidas para a célula, convivendo com as máquinas antigas, para evitar-se
16.É o que mostra, por exemplo, os trabalhos de Christophe Dejours 1991). 
17. Os artigos ou modelos são identificados por números ou códigos. o deslocamento. Quando isso acontece, não é apenas a operação que muda, mas a função.

Vejamos esse tópico de maneira mais detida, porque ele é indicativo do deslizamento de sentido do termo "qualificação", em direção agora a uma definição mais restrita. Um mesmo tipo de máquina (a galoneira, por exemplo, do caso visto mais acima) pode servir ao artigo de número $643 \mathrm{ou}$ $978^{17}$, ambos cumprindo funçōes diferentes. "Função" e "posto de trabalho" têm aqui significados apenas parcialmente semelhantes. Quando porventura a máquina dedicada a um novo modelo não cabe no espaço físico da célula para a qual é trazida, por entre as ilhas, ela pode ser alocada em outra célula próxima, que também possa fazer uso dela. Acompanham-na algumas costureiras. Porém, quando o novo modelo exige que a costureira apenas realize a mesma operação a que está acostumada em sua célula de origem, então não há necessidade de deslocamento. Nenhuma das duas alternativas é uma aproximação exata do que se pode chamar de "função".

Esse relato confirma dois elementos do sistema. Em primeiro lugar, o fato de que a fidelidade da célula obedece primordialmente ao planejamento do produto e da quantidade e diversidade de produtos que cada célula é capaz de dar conta. Os problemas de coordenação do trabalho, tanto no interior da célula como entre as células, quando vários produtos são demandados, não são de menor monta e acabam dando lugar a arranjos ad hoc do tipo antes descrito pela informante - nesse caso, ocorre uma "invasão" de uma célula por outra (o deslocamento de operárias na verdade não é incomum, pois é solicitado também no acabamento). Em segundo lugar, o fato de que a qualificação está em função não apenas da operação padronizada (corte, overlock, galoneira, colocação de elástico etc.), mas às vezes da característica de um produto único, dada a especialidade requerida. Somente quando o novo modelo exige o uso de maquinário diferente é que se faz necessária a migração do serviço de parte da célula para outra; quando isso não ocorre, a costureira continua na célula de origem, manufaturando uma parte do produto que no entanto será incorporada no novo modelo: ela usa a mesma máquina como uma espécie de "base" de manufatura de um componente universal que entra no leque de artigos da empresa como, por exemplo, o elástico, o qual, ainda que sirva para o novo modelo, serve também para os outros, e a costureira pode continuar na mesma máquina especializada. Mas há situações em que a maneira de colocar o elástico define uma "função" - por exemplo, no caso da cueca infantil. A "função", portanto, nesse caso, recobre o modelo ou artigo inteiro. É isso que 
permite dizer que um novo modelo alterou a "função", embora aparentemente ela seja a mesma (colocação do elástico). A habilidade, o treinamento ou a qualificação no manuseio de uma máquina especializada, nesse exemplo, não esgota completamente a "função", pois ela agora depende de uma distinção, quer técnica, quer de modo de operação.

A flexibilidade produtiva joga com as qualificaçōes de sempre, sem ter de criar outras, exceto naqueles casos em que o novo modelo exige uma operação melindrosa, diferente do estoque já existente - mas, ainda nesse caso, apenas para uma parte do processo. A confusão das terminologias expressa a indeterminação do trabalho: se a "função", na sintaxe do velho modelo produtivo, era associada imediatamente à qualificação do posto, no modelo produtivo das células ela perde seu significado coletivo (e apropriável institucionalmente) para se particularizar em produtos da empresa: muda a função quando muda a máquina que fabrica um produto específico (patente, segredo industrial etc.) da empresa. Mesmo assim, tal particularização não é excludente de um reconhecimento social, via mercado: as costureiras da empresa, como são bem treinadas, encontram emprego em outras confecções. As outras empresas, concorrentes de igual porte ou menores, sabem disso, e as trabalhadoras também: no questionário, 34\% responderam que teriam possibilidade de encontrar um novo emprego (mesmo que em outra função), e 31\% afirmaram que encontrariam com facilidade um novo emprego porque as trabalhadoras da Empresa A são muito bem treinadas. $\mathrm{O}$ que quer dizer que o trabalho efetuado ali pode, sim, ser aproximado de outros. No entanto, o mais impressionante é a relativa sem-cerimônia com que a função pode prescindir de uma definição precisa em termos de localização: afinal, a função é - ou foi - base para a construção de critérios de classificação de qualificações que entram na composição da grade salarial. Talvez isso ocorra porque a relação salarial na empresa depende mais do prêmio: o salário de base expressa, em tese, qualificações coletivamente avalizadas (as quais, aliás, no caso das atividades de costura, não parecem ser muito variadas: ajudante, overloquista, trabalhadora de galoneira etc.); se ele é baixo, o prêmio faz a diferença e, logo, mais importante do que o salário mediano entre as faixas de qualificação está a possibilidade de aumentar o rendimento via prêmio. Como este último é o que funciona como referência, não é a qualificação mediana que conta, mas aquela que permite chegar mais rapidamente ao prêmio. Essa é a "função" que freqüenta a linguagem das informantes para designar aquilo que é feito por elas mesmas; uma terminologia que vem de cima porque provavelmen- 
te é mais fiel às mudanças rápidas de modelo ou artigo - mais do que associar "função" ao acompanhamento de máquinas mais ou menos "universais" na costura.

O acabamento, ao contrário, não exige a troca de máquinas; por ser fixo, ou seja, sem a possibilidade de deslocamento entre as células, permite também um maior acomodamento no sentido de adequação do trabalhador ao posto: "Pra mim é mais fácil ficar no acabamento do que ir trabalhar na outra máquina, porque eu rendo... a minha produtividade no acabamento é muito maior do que numa outra máquina. Pelo modo de trabalho, [nos casos em que] o artigo é diferente" (costureira, célula 14). Assim, uma função pouco nobre de um ponto de vista do "ofício" (acabamento) é preferível àquelas mais dinâmicas, nas quais, no entanto, em compensação, a carga de trabalho é maior. Volta aqui, mais uma vez, a nostalgia do período em que não vigorava todo o modernismo da organização celular.

Por outro lado, deve-se notar que o costume das antigas costureiras no trato de suas próprias funções, ou seja, sua qualificação desde sempre exercitada quando a fábrica ainda se localizava em São Paulo e já com as células, não é sumariamente descartável: mesmo com o aproveitamento de muita gente nova que mora na região ou nas redondezas do novo endereço, houve certa dificuldade de repor a antiga força de trabalho, pelo menos em um primeiro momento. "Elas não tinham o mesmo ritmo de trabalho que a gente. Eles não podem dispensar os antigos porque não é tão fácil fazer as funçôes que a gente faz" (Idem).

A seleção do pessoal "certo" para cada tipo de operação não é fruto de um processo planejado e objetivo; longe disso, é muito mais empírico e indutivo. Assim, o que ocorre na realidade é que, diante da necessidade de treinamento em uma nova máquina ou em uma operação nova para a costureira, experimentam-se várias operárias até que se encontre aquela mais produtiva: "Muitas vezes eles fazem a troca da costureira de uma máquina para outra máquina para ver se é mais vantagem, principalmente quando se troca de artigo: então, às vezes muda para ver [em que posto] a pessoa que se dá melhor" (idem). Na falta de um treinamento elaborado, a adequação da operária ao posto é medida na prática: entra-se "com a cara e a coragem" e o aprendizado "vai de sopetão", para ver se a pessoa "pega o jeito".

A Empresa B, embora seja menor em relação à sua contraparte da amostra, também sofre variações recorrentes de modelo/artigo. Os pedidos das montadoras de veículos encetam um dinamismo tão ou mais frenético que 
o da confecção de roupas íntimas. Mas a percepção do treinamento entre as costureiras dessa empresa é menos reconfortante. Na região (Itaquacetuba), a concorrência em termos de mão-de-obra vem de uma empresa de outro ramo (colchões), que fica à espreita, pronta para absorver as operárias que, por algum motivo, saem da Empresa B. No questionário, 44\% delas disseram que teriam muita dificuldade em arranjar um novo trabalho por causa do desemprego. Um percentual menor (37\%) admitiu que encontraria um novo emprego com facilidade, porque são muito bem treinadas.

\section{Balizas de uma deriva de classe}

Há muitas maneiras de abordar a problemática das classes sociais. Mesmo considerando todas as mudanças do capitalismo nos últimos anos (das quais as células de produção são uma expressão mediada pelo novo formato da empresa), essa problemática ainda nos parece pertinente. Exemplos de estudos monográficos recentes orientados por essas mudanças mostram que o desafio de articular a estrutura social e as açôes de grupos e coletividades precisamente demarcados no tecido industrial vem sendo perseguido ${ }^{18}$. Neste trabalho, não são discutidos aspectos da formação, da consciência ou da luta de classes. Limitamo-nos a uma consideração pontual, empiricamente circunscrita, a fim de tentar responder à seguinte pergunta: Quais mudanças estão ocorrendo na morfologia da classe, a partir dos novos modelos de organização industrial que as empresas vêm implantando no Brasil? Mesmo que a classe não perceba a si mesma como classe, na interpretação que lhe dá Edward Thompson (1968, pp. 9-15), é inegável que algumas características distinguem - mesmo que de maneira estática - um segmento preciso da população trabalhadora como participante do mundo industrial, na condição de assalariamento. Partindo dessa evidência e da pergunta inicial, tentamos obter algumas indicações com base em nossa pesquisa, as quais seguem uma direção que pode ser resumida em quatro tópicos: 1) tendência à privatização do coletivo, entendido como tradução de uma determinada experiência de classe; 2) processo de individualização, observado tanto do ponto de vista da formação do salário como da organização do trabalho; 3) reiteração da exclusão, isto é, quanto mais o modelo se aprofunda (just-in-time, qualidade total etc.), mais excludente se torna - em outros termos, uma contradição: quanto mais o modelo dá certo, mais ele desemprega ou promove a insegurança - com a diferença (importante) de que o sujeito que exclui é membro do próprio coletivo; 4) deslocamento do lugar onde
18. Ver o trabalho de Estanque (2000), sobre os trabalhadores do setor de calçados na região de São João da Madeira, Portugal. 
19. Uma dificuldade adicional no caso brasileiro é a persistência de um padrão em que a experiência de classe passa historicamente pelo sindicato, seja em virtude do corporativismo, seja, paradoxalmente, por conta do "paradigma ABCD” (crítico do corporativismo), que se tornou nos últimos anos um modelo "desejado" por outros sindicatos e lideranças. De qualquer modo, experiências coletivas ou solidárias da parte do trabalho sem a concorrência do sindicato (ou de uma organização referida a ele) não são muito visíveis. está situado o conflito: para além de um conflito interclasses, observa-se também um conflito intraclasse que de alguma forma "pacifica" o primeiro. Esses quatro tópicos reforçam-se mutuamente, oferecendo um quadro coerente que fornece inteligibilidade ao movimento e ao juízo dos atores na situação de trabalho.

Somente dessa maneira pode-se interpretar a irrelevância da presença sindical nas empresas estudadas. Na verdade, o contingente que desconsidera a ação dos sindicatos sofre já os efeitos da organização celular. Se $50 \%$ a $60 \%$ das respondentes do questionário, assim como a totalidade das informantes em situação de entrevista, não vêem o sindicato como uma baliza importante do cenário da vida ordinária de trabalho, não é porque não o conheçam ou porque ele não exista, mas exatamente porque as células de produção conspiram contra a formação de identidades coletivas. Enfim, mesmo que o sindicato fosse presente, isso não anularia o fato de que o tipo de organização celular é "anti-sindical", sem precisar dizê-lo abertamente. É a indiferença - e não o recolhimento em função de uma derrota política que é o traço saliente da situação entre as classes.

Por outro lado, a impotência do sindicato não significa o cancelamento da experiência de classe. Essa última, aliás, pode existir mesmo sem sindicato ou mesmo de maneira fragmentada, ou seja, ela não passa necessariamente pela conversão da experiência coletiva em instituição (sindicato). Grande parte do debate nos primórdios do "novo sindicalismo" no Brasil freqüentou esse tipo de dilema ${ }^{19}$. A questão hoje aparenta ser mais séria e poderia ser apresentada da seguinte maneira: segundo o quadro de significação acima referido, tudo parece conduzir à conclusão de que nas células de produção não é gerado nenhum tipo de conflito de classes. É essa a conexão entre experiência de trabalho e experiência de classe. Uma conexão pela negativa. Sabemos que tal inferência, bastante geral, emitida a partir de casos pontuais circunscritos temporal e espacialmente, pode parecer um tanto arriscada. Mas a alternativa de acumular várias experiências diferentes de células de produçáo ou trabalho em grupo, para em seguida qualificar uma experiência de classe, levaria à perda do ponto central de nosso argumento.

Vejamos, agora, a título conclusivo, como se comportam os dados de campo descritos ao longo do texto diante do pano de fundo da breve discussão encetada nesta última seção.

A experiência das costureiras das duas fábricas analisadas mostra, no que respeita à identidade de classe social, duas faces que não formam uma unidade significativa; ao contrário, encontram-se em planos que não se cru- 
zam. Por um lado, elas não são propriamente "excluídas" do mercado de trabalho, porque seu acesso ao mundo do trabalho se dá por meio de um estatuto formal. São, portanto, inquestionavelmente participantes da classe trabalhadora. Por outro lado, tal participação não desemboca em uma ação autônoma, reivindicativa ou diferenciada. O plano da situação econômica no mercado e da relação com a classe antagônica não corresponde ao plano da ação. Grande parte do descompasso entre os dois planos é reforçado pela organização do trabalho em "células", que promove o controle recíproco entre membros do grupo e a responsabilização "para baixo", isto é, dos quadros gerenciais até o pessoal operacional, passando por supervisoras e coordenadoras. Finalmente, a polivalência forçada, alicerçada nas altas taxas de absenteísmo e na necessidade de dar conta dos pedidos, deixa entrever, paradoxalmente, a importância da qualificação para cada posto em particular, e não o seu abandono em nome de uma abertura para múltiplas competências profissionais simultâneas: as próprias operárias sabem disso, e valorizam o treinamento e a qualificação adquirida na firma, mesmo que signifique uma intensificação do ritmo, porque o destino fora da empresa pode eventualmente requerer tal qualificação, encarada como um bem próprio, e não da empresa.

Em outro âmbito, o da remuneração, a percepção de que o sistema de trabalho individual era melhor do que o coletivo demonstra a inadequação das filosofias integracionistas de organização do trabalho e seu pendor comunitário, quando confrontadas com as escolhas das próprias envolvidas diante dos resultados de um ajuste incerto entre o grupo e as capacidades de trabalho de cada uma, além de uma dose de arbitrariedade pairando no interior do grupo quando a "maioria" pode excluir, por alguma razão, a "minoria".

Os novos métodos de produção, dos quais as células são um exemplo, convertem uma parte do antigo e desaparecido discurso pela autonomia no trabalho (ou por um "trabalho autônomo") - discurso que não acompanha a população visada nesta pesquisa em particular, mas que é de qualquer modo patrimônio da classe social à qual ela pertence - em um instrumento de exclusão e controle das próprias colegas (ver a seção "A exclusão do grupo"). A possibilidade de sair da monotonia da linha e abraçar novos modos de produzir, com máquinas e desafios diferentes - mesmo que parcamente limitada pelo campo de alternativas técnicas que as fábricas oferecem -, contém um apelo que não passa completamente despercebido, ainda mais porque novas qualificações são vistas também como formas de se libertar da dependência de uma única empresa, como observado no decorrer do texto. Porém, a rotação pelos 
20. Tal racionalização pode envolver também, como foi o caso de uma das empresas da pesquisa, a mudança de localização da planta. postos da "ilha” ou entre diferentes células segue uma modulação flexível, buscando encurtar os tempos de espera de produtos semi-acabados e racionalizando ao máximo o emprego da força de trabalho ${ }^{20}$. Nesse desenho, o grupo é autônomo para ajustar mais prontamente o componente do trabalho humano ao mecanismo de simultaneidade de manufatura de artigos que o modelo comporta. A situação mais próxima da ideal seria aquela em que a figura da supervisora ou da encarregada deixaria de ter uma conotação coercitiva, passando a ser apenas consultiva, para os casos em que o grupo não pudesse, ele próprio, deliberar. Uma situação em que não fosse necessário dizer o que é preciso fazer, mas em que cada uma decidisse segundo seu próprio "juízo".

Nesse caso, a microcoletividade da célula pode chegar a decidir, autonomamente, pela impertinência da classe.

\section{Referências Bibliográficas}

Dejours, Christophe. (1991), A loucura do trabalho. São Paulo, Oboré/Cortez.

Durand, J. P. (2003), "A refundação do trabalho no fluxo tensionado". Tempo Social, 1 (15): 139-158.

Esping-Andersen, Gösta. (1990), The three worlds of welfare capitalism. Cambridge (UK), Polity Press.

ESTANQUE, Elísio. (2000), Entre a fábrica e a comunidade: subjectividades e práticas de classe no operariado do calçado. Porto, Afrontamento.

FORD, Henry. (1954), "Minha vida, minha obra”. In: __. Os princípios da prosperidade. Rio de Janeiro, Brand.

Fournier, Pierre. (1996), "Deux regards sur le travail ouvrier". Actes de la Recherche en Sciences Sociales, 115: 80-93, décembre.

Mello E Silva, Leonardo. (2004), Trabalho em grupo e sociabilidade privada. São Paulo, Editora 34/Curso de Pós-Graduação em Sociologia da USP.

Montgomery, David. (1980), Worker's control in America: studies in the history of work, technology and labor struggles. Cambridge, Cambridge University Press.

Nelson, Daniel. (1984), “Le taylorisme dans l'industrie américaine, 1900-1930”. In: Montmollin, Maurice de \& PAstré, Olivier. Le taylorisme. Paris, La Découverte, pp. 51-66.

TaYlor, F. W. (1987), Princípios de administração científica. 7 ed. São Paulo, Atlas.

Thompson, Edward P. (1968), The making of the English working class. Middlesex, Penguin Books.

Zarifian, Philippe. (1998), Travail et communication: essai sociologique sur le travail dans la grande entreprise industrielle. 2 ed. Paris, PUF. 


\section{Resumo}

O Trabalho visto de baixo

O texto detém-se sobre um tipo particular de organização do trabalho, chamado de células de produção, aplicado em fábricas do ramo de confecção em São Paulo, focando a experiência das operárias que trabalham sob esse formato. Vários aspectos são ressaltados a partir dele, tais como o sistema de remuneração, a regulação do/pelo grupo, o treinamento e as exigências de qualificação, a flexibilidade produtiva e o significado, para o grupo operário, do deslocamento geográfico de unidades de produção. Tais aspectos aparecem como contraponto à experiência coletiva que conformou uma identidade de classe, hoje em processo de aparente decomposição. Uma das razões para isso seria o sucesso de iniciativas privativas e confinadas ao espaço da empresa, das quais as células de produção são um exemplo. A descrição pormenorizada de casos concretos pretende contribuir com alguns elementos para uma apreciação compreensiva do fenômeno e suas implicações teóricas para o debate sobre as classes sociais.

Palavras-chave: Organização do trabalho; Pós-fordismo; Classe social; Flexibilidade; Manufatura celular.

\section{Abstract}

\section{Work viewed from below}

This paper approaches a particular type of work organization called production cells. That model is analized in its application through plants in the garment industry, in the state of São Paulo, Brazil. It focused on the working women experience under that work model, from which some aspects are stressed in this paper such as the payment system, the regulation of work by/of the worker's group, the training and its skill features, the productive flexibility, and the meaning of the geographical plant delocalisation to the worker group itself. Such aspects appear to be a counterpoint to the collective experience that moulded class identity in the past and that is, nowadays, being destroyed. One of the reasons for that fact is supposed to be the well-established private initiatives made by companies related to their workforce. This kind of strategies, among which production cells are a good example, circumscribe the labor contest to the inner space of the company level. The detailed report of cases discussed here intend to contribute with some elements to a comprehensive appreciation of the work organization debate as well as its further theoretical inferences in terms of the social class paradigm.

Keywords: Work organization; Post-fordism; Teamwork; Social class; Flexibility.

Texto recebido em 11/ $11 / 2004$ e aprovado em $1 / 9 / 2005$.

Leonardo Mello e Silva é professor do Departamento de Sociologia USP. E-mail: leogmsilva @hotmail.com

William Vella Nozaki foi bolsista IC Fapesp (2002-2004).

Vladimir Ferrari Puzone foi bolsista IC PibicCNPq (2003). 